Article

\title{
Developing a Risk Reduction Support System for Health System in Iran: A Case Study in Blood Supply Chain Management
}

\author{
Ali Sibevei ${ }^{1}$, Adel Azar ${ }^{1}$, Mostafa Zandieh ${ }^{2} \mathbb{D}$, Seyed Mohammad Khalili ${ }^{3} \mathbb{D}$ and Maziar Yazdani ${ }^{4, *}$ \\ 1 Department of Industrial Management, Faculty of Management and Economics, Tarbiat Modares University, \\ Tehran 14115-111, Iran; alisibevei@modares.ac.ir (A.S.); azara@modares.ac.ir (A.A.) \\ 2 Department of Industrial Management and Information Technology, Management and Accounting Faculty, \\ Shahid Beheshti University, Tehran 1983969411, Iran; m_zandieh@sbu.ac.ir \\ 3 Department of Industrial Engineering, Faculty of Engineering, Khayyam University, \\ Mashhad 9189747178, Iran; m.khalili@khayyam.ac.ir \\ 4 School of Built Environment, University of New South Wales, Kensington, Sydney, NSW 2052, Australia \\ * Correspondence: maziar.yazdani@unsw.edu.au
}

Citation: Sibevei, A.; Azar, A.; Zandieh, M.; Khalili, S.M.; Yazdani, M. Developing a Risk Reduction Support System for Health System in Iran: A Case Study in Blood Supply Chain Management. Int. J. Environ. Res. Public Health 2022, 19, 2139.

https://doi.org/10.3390/

ijerph19042139

Academic Editors: Izabella Lecka, Sally Brailsford, Remigiusz Kozlowski and Józef Haczyński

Received: 2 January 2022

Accepted: 10 February 2022

Published: 14 February 2022

Publisher's Note: MDPI stays neutral with regard to jurisdictional claims in published maps and institutional affiliations.

Copyright: (c) 2022 by the authors. Licensee MDPI, Basel, Switzerland. This article is an open access article distributed under the terms and conditions of the Creative Commons Attribution (CC BY) license (https:// creativecommons.org/licenses/by/ $4.0 /)$.

\begin{abstract}
Health systems are recognised as playing a potentially important role in many risk management strategies; however, there is strong evidence that health systems themselves have been the victims of unanticipated risks and have lost their functionality in providing reliable services. Existing risk identification and assessment tools in the health sector, particularly in the blood supply chain, address and evaluate risks without taking into account their interdependence and a holistic perspective. As a result, the aim of this paper is to develop a new systemic framework based on a semi-quantitative risk assessment approach to measure supply chain risks, which will be implemented through a case study on the Iranian BSC. This paper identifies and assesses supply chain risks (SCRs) by employing a novel systemic process known as SSM-SNA-ISM (SSI). First, the supply chain and its risks are identified using Soft Systems Methodology (SSM). Then, given the large number of risks, the second stage uses Social Network Analysis (SNA) to identify the relationships between the risks and select the most important ones. In the third stage, risk levelling is performed with a more in-depth analysis of the selected risks and the application of Interpretive Structural Modelling (ISM), and further analysis is performed using the Cross-Impact Matrix Multiplication Applied to Classification (MICMAC). The study found that by using the new proposed approach, taking into account risk relationships, and taking a holistic view, various supply chain risks could be assessed more effectively, especially when the number of risks is large. The findings also revealed that resolving the root risks of the blood supply chain frequently necessitates management skills. This paper contributes to the literature on supply chain risk management in two ways: First, a novel systemic approach to identifying and evaluating risks is proposed. This process offers a fresh perspective on supply chain risk modelling by utilising systems thinking tools. Second, by identifying Iranian BSC risks and identifying special risks.
\end{abstract}

Keywords: supply chain risks; blood supply chain; interpretive structural modelling; social network analysis

\section{Introduction}

While the supply chain (SC) concept has attracted interest among academics, policymakers, and companies [1-3], its success in any organisation may be compromised by a variety of factors, including high demand volatility, short product life cycles, and varying customer requirements [4,5]. Addressing these issues is difficult due to the complex nature of SCs [6]. Hendricks and Singhal [7] asserted that due to a lack of proper risk management, $\mathrm{SC}$ issues may significantly reduce profits. In general, risk management entails identifying, 
analysing, and controlling risks [8]. Identifying and mitigating risks in SCs is accomplished not only at the company level, but also by focusing on the entire SC [9]. SCs are vulnerable to a variety of sources of uncertainty $[10,11]$. With the rise in uncertainties and risk events, supply chain risk management (SCRM) has received more attention than ever before and has become critical to business success $[12,13]$. Therefore, organisations need to learn how to mitigate the adverse impacts of risks associated with supply chain [14].

SCRM is being explored in many sectors such as health systems; however, some of them are more vulnerable due to the high complex interactions between their components [15-17]. Furthermore, unpredictability makes it difficult to manage and meet the needs of the patients. As a result, the unpredictability of SCs creates risks that have a direct impact on people's lives. The performance of blood-related services in healthcare systems, on the other hand, is critical [18]. Because blood is the fluid in the body that supplies the necessary substances to the human body, it plays an important role in experiences such as accidents or emergencies [19]. Human disease is causing an uncontrollable demand for blood. It also comes from donors who volunteer to donate, so variations in blood supply and demand are unavoidable. Because blood has a short life span, it is a perishable product, and the blood centre should manage and distribute blood products in a complex, uncertain environment, which may pose a risk to the blood SC (BSC). There are many unanswered questions about the blood supply chain that need to be addressed, particularly in terms of risk management.

While numerous researchers have recognised the important role of reliable blood supply chain systems in the health sector, little research has been conducted on these systems' vulnerability to providing reliable services. Blood supply chains have always been associated with a wide variety of risks, particularly in countries with poorly planned health systems, which should be identified and addressed concurrently. While the majority of studies have focused exclusively on one of these factors, more holistic approaches are required. Numerous techniques have been used, including the Delphi method, checklists, module decomposition, and scenario analysis. However, because there is no one-size-fits-all approach to risk identification, finding novel approaches is always an open research avenue. Additionally, many studies have used tools such as Failure Mode and Effects Analysis (FMEA) and multi-criteria decision-making (MCDM) during the risk assessment stage, but these methods do not take into account the relationship between risks. Additionally, when the number of identified risks is limited, methods such as the Analytic Network Process (ANP) or Interpretive Structural Modelling (ISM) are used, which make these methods unsuitable for the blood supply chain.

By addressing the aforementioned gaps, this study aims to add new theoretical and practical insights to a growing body of knowledge about reducing risks associated with blood supply chains in health systems, particularly in countries where the health sector is becoming increasingly vulnerable to unexpected risks. Therefore, the main contributions can be summarised in the following way.

This study contributes to the growing body of knowledge by proposing an integrated approach based on SSM, SNA, and ISM methods to identify and evaluate risks associated with the blood supply chain and then implement the proposed approach in a real-world case study. Risks are identified in the proposed system by creating a rich image that is then used to answer the preceding questions within SSM. Rich images offer a comprehensive and macro view of the situation. Thus, the blood supply chain and its components are depicted, followed by identifying the risks associated with the segments. The following step examines the relationships between identified risks in order to analyse and evaluate them. Since SNA is capable of analysing multiple variables, the most significant risks are identified using a relationship-based approach. The ISM method is then used to determine the relationships between the reduced key risks, allowing for a more in-depth analysis.

Due to the importance of SCRs particularly in healthcare SCs and the problem of risk assessment techniques when the number of risks is high, "The central aim of this study is to develop an approach to support decision makers in coping with the challenge of risks 
currently faced by health systems to evaluate risks by taking a holistic view of the BSC using systemic tools". The research questions that are addressed by this study are:

Question 1: How can we identify risks in a systemic way?

Question 2: How can we evaluate the high number of risks regarding their relationships?

Question 3: What are the most important SCRs in Iran's blood SC?

The paper has been structured as follows: Section 2 provides a literature review about blood SCRs and risk assessment techniques. Section 3 deals with methodology and provides information about each step. Section 4 presents the practical implementation of the new proposed methodology in the Iranian BSC. Finally, the conclusion and managerial insights are explained in the last section.

\section{Literature Review}

Below is a review of the related literature in two distinct but related research streams.

\subsection{Blood Supply Chain \\ Healthcare and Blood Supply Chain}

Healthcare systems are becoming increasingly complex and uncertain. Every step of the healthcare decision-making process involves an element of uncertainty. There are numerous risks associated with all aspects of healthcare, from diagnosis to treatment to rehabilitation. Incorrect assessments can have unintended negative consequences that, by the time they are discovered, have already had an impact [20]. Healthcare risks are characterised by their complexity, the possibility of patient harm and uncertainty, and the possibility of serious outcomes with serious consequences. According to the US Institute of Medicine, approximately $10 \%$ of patients admitted to hospitals experience adverse events, the majority of which are preventable [21]. Blood and its derivatives are among the most critical items used in healthcare because there is no substitute [19]. Any patient's treatment can be harmed by a lack of blood. The expiration of blood will result in an increase in the cost of blood transfusions [22]. There are several potential risks associated with blood function that can impair the healthcare network's overall performance [23].

\subsection{Risk Assessment Techniques}

This section reviews important studies on SCRs in healthcare and other fields. In the first part, a literature review on healthcare and blood supply chain risks is presented and in the second part other areas are reviewed.

\subsubsection{Healthcare and Blood Supply Chain}

Lu et al. [24], in an article using PDCA and FMEA methods, studied the RPNs before and after recovery while discussing the failure states of the blood transfusion process in China. Dehnavieh et al. [25] conducted a study to actively assess the risks of a blood transfusion process in a paediatric emergency education centre using the Health FMEA (HFMEA) method. Najafpour et al. [26] evaluated the blood transfusion process in a public hospital using FMEA. The results showed that mistransfusion is the most critical risk leading to severe morbidity or mortality. Cagliano et al. [27] merged three well-known risk management tools, namely Risk Breakdown Structure (RBS), Risk Breakdown Matrix (RBM), and FMECA, to provide a structured approach for identifying and analysing riskrelated causes. Achmadi and Mansur [28] attempted to minimize the level of effective risk in the BSC using House of Risk (HOR). The results showed that eleven risk factors were needed to be prioritized by seven possible mitigation measures. Jaberidoost et al. [29] assessed risks in the pharmaceutical industry in Iran concerning the process, priorities, hazards, and risk probability. Risk analysis was performed using Analytic Hierarchy Process (AHP), rating scale, and SAW. Boonyanusith and Jittamai [23] examined the risks involved in the BSC to assess risks and evaluate their management practices using HOR. Mora et al. [30] used FMEA to evaluate potential failures and improve blood transfusion safety in an urban hospital. Each failure condition was evaluated using the probability of 
occurrence, severity, and probability of detection. Liu [20] proposed a new risk priority approach combining cluster analysis and prospect theory with FMEA when a large pool of experts was present. They also proposed an entropy-based approach to objectively weighing the risk factors using risk assessment information.

\subsubsection{Other Areas}

Risk assessment and identification studies are presented in other areas in the following. Gaudenzi and Borghesi [31] used the AHP method to identify SCR factors to improve customer value. Wu et al. [32] used AHP to rank suppliers' risk factors and develop a method for hierarchically classifying inbound supply risk factors. Pujawan and Geraldin [33] developed a framework for actively managing SCRs using HOR and presented a combination of core ideas from two well-known house of quality tools and FMEA. Moeinzadeh and Hajfathaliha [34] employed a combination of fuzzy sets, ANP and VIKOR for SCR assessment. Wang et al. [35] presented a risk assessment model capable of the structural analysis of aggregative risk implementation of various green schemes in the fashion SC. They used fuzzy AHP to calculate Aggregative Risk Index (ARI). Song et al. [36] investigated the major risk factors of Sustainable SCM (SSCM) based on rough logic and Decision-Making Trial and Evaluation Laboratory (DEMATEL) method. Curkovic et al. [37] tried to find out how corporate SCRs are managed with a particular focus on the use of FMEA and how FMEA can play an important role in the process of risk management through supplier evaluation and selection. Nazam et al. [38] used a fuzzy AHP to calculate the weight of each of the risk criteria and proposed the TOPSIS technique for ranking and evaluating the related risks in a green SC. Fazli et al. [39] identified the major risks associated with crude oil SC. They used DEMATEL to determine the interdependence between risks and then used ANP to assess the significance of each risk. Rostamzadeh et al. [40] developed a framework for sustainable SCRM (SSCRM) using TOPSIS and CRITIC. Taking a holistic view, Junaid et al. [41] combined neutrosophy with AHP and TOPSIS and implemented this hybrid approach in an automobile industry. A summary of the previous studies presented in the Table 1.

A review of the blood-related literature indicates that most of the previous studies focused on a part of an SC and only a few studies have discussed the issue of risk in the blood SC $[23,28,29]$. Furthermore, only a few studies in this field, such as Jaberidoost, Olfat, Hosseini, Kebriaeezadeh, Abdollahi, Alaeddini, and Dinarvand [29], have used MCDM methods to identify risks. To study the methods used to identify and evaluate risks, SCRs have been studied in other areas as well. The results show that most of the studies have employed MCDM methods such as CRITIC and TOPSIS [40], ANP and VIKOR [34], and AHP TOPSIS [38]. Whereas in our proposed hybrid approach, the SC is first investigated using SSM and the risks are identified. Then, the combined SNA-ISM approach is used due to the high number of risks and taking the relationships among them into account. Many of the approaches mentioned in the above research works are not capable of considering relationships or are not suitable for a high number of risks; the novelty of the presented work is to achieve these two issues utilizing the SNA-ISM hybrid approach. According to our findings, no study has used the proposed method yet, and it can be said that the present study is innovative from this perspective. 
Table 1. Summary of previous studies.

\begin{tabular}{|c|c|c|c|c|}
\hline & Author's Name & Year & Approach & $\begin{array}{l}\text { Study } \\
\text { Area }\end{array}$ \\
\hline \multirow{9}{*}{ 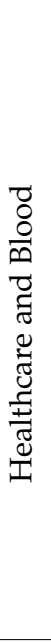 } & Liu [20] & 2009 & $\begin{array}{l}\text { FMEA and Cluster } \\
\text { analysis }\end{array}$ & \multirow{8}{*}{$\begin{array}{l}\text { Other } \\
\text { methods }\end{array}$} \\
\hline & Boonyanusith and Jittamai [23] & 2019 & HOR & \\
\hline & Lu, Teng, Zhou, Wen and Bi [24] & 2013 & PDCA and FMEA & \\
\hline & $\begin{array}{l}\text { Dehnavieh, Ebrahimipour, Molavi-Taleghani, Vafaee-Najar, Noori Hekmat } \\
\text { and Esmailzdeh [25] }\end{array}$ & 2015 & HFMEA & \\
\hline & Najafpour, Hasoumi, Behzadi, Mohamadi, Jafary and Saeedi [26] & 2017 & FMEA & \\
\hline & Cagliano, Grimaldi, Mangano and Rafele [27] & 2017 & $\begin{array}{l}(\mathrm{RBS}),(\mathrm{RBM}) \\
(\mathrm{FMECA})\end{array}$ & \\
\hline & Mora, Ayala, Bielza, Ataúlfo González and Villegas [30] & 2019 & HOR & \\
\hline & Achmadi and Mansur [28] & 2018 & HOR & \\
\hline & $\begin{array}{l}\text { Jaberidoost, Olfat, Hosseini, Kebriaeezadeh, Abdollahi, Alaeddini and } \\
\text { Dinarvand [29] }\end{array}$ & 2015 & AHP and SAW & MCDM \\
\hline \multirow{13}{*}{  } & Curkovic, Scannell and Wagner [37] & 2013 & FMEA & \multirow{3}{*}{$\begin{array}{l}\text { Other } \\
\text { methods }\end{array}$} \\
\hline & Troche-Escobar, et al. [42] & 2018 & ISM & \\
\hline & Pujawan and Geraldin [33] & 2009 & HOR & \\
\hline & Wu, Blackhurst and Chidambaram [32] & 2006 & AHP & \multirow{10}{*}{ MCDM } \\
\hline & Gaudenzi and Borghesi [31] & 2006 & AHP & \\
\hline & Wang, Chan, Yee and Diaz-Rainey [35] & 2012 & FAHP & \\
\hline & Song, Ming and Liu [36] & 2018 & DEMATEL & \\
\hline & Fazli, Kiani Mavi and Vosooghidizaji [39] & 2015 & DEMATEL and ANP & \\
\hline & Junaid, Xue, Syed, Li and Ziaullah [41] & 2020 & N-AHP and TOPSIS & \\
\hline & Moeinzadeh and Hajfathaliha [34] & 2009 & ANP and VIKOR & \\
\hline & Nazam, Xu, Tao, Ahmad and Hashim [38] & 2015 & AHP and TOPSIS & \\
\hline & Fazli, Kiani Mavi and Vosooghidizaji [39] & 2015 & DEMATEL and ANP & \\
\hline & Rostamzadeh, Ghorabaee, Govindan, Esmaeili and Nobar [40] & 2018 & CRITIC and TOPSIS & \\
\hline
\end{tabular}

\section{Methodology}

This study presents an integrated framework based on qualitative and quantitative approaches to identify and assess risks in the BSC. Contextualization entails defining the risk management process' scope, defining the organization's objectives, and establishing risk evaluation criteria. The context is made up of external factors (regulatory environment, market conditions, stakeholder expectations) and internal factors (governance, culture, standards and rules, capabilities, existing contracts, employee expectations, information systems, and so on). In the first step, the qualitative analysis uses the rich picture within SSM to identify the risks of the BSC. Thus, according to the internal and external categorization [43], the internal and external segments' relations in the BSC are identified using the rich picture. Then, identifying the risks is done by reviewing the literature and interviewing the experts. Purposive sampling was used to select experts for this study. The experts included the general manager of Iranian blood transfusion, the manager of the IT department, 2 people from the blood donation department, the equipment technical managers ( 2 people), 2 people from the quality assurance department, 2 people from the blood bank department, and the accreditation manager of the blood transfusion organization. As mentioned earlier, when the number of risks is high, MCDM methods are not efficient, so in the second step of quantitative analysis, using the SNA approach, the importance of 
risks is derived based on their relationships by the degree of centrality index. Then, using the quartile score, the highest degrees are determined. If the degree of centrality is higher, the risk becomes more important, so the most important risks in the SC are those that are in the last quartile (high-risk) and are selected for further analysis. In the third step, the ISM approach examines the relationships among these key risks. The research steps that describe the methods are illustrated in Figure 1.

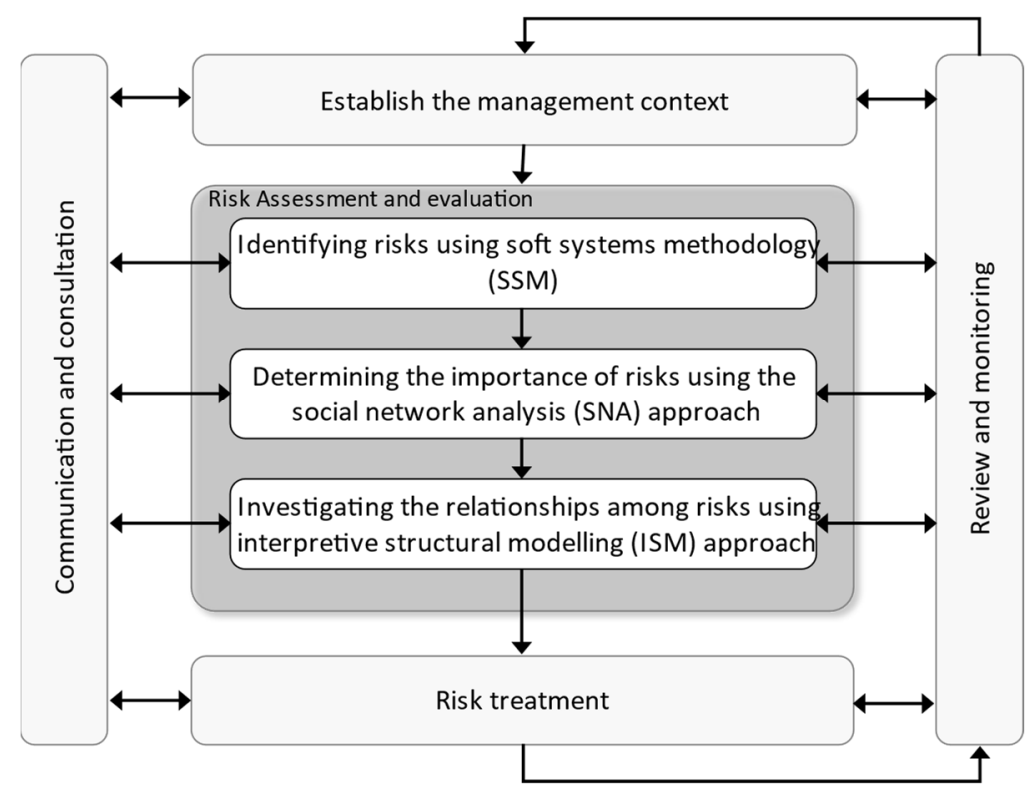

Figure 1. Steps of the proposed framework.

Monitoring and reviewing include assessing risk management performance with indicators that are assessed on a regular basis for adequacy. It entails checking for deviations from the risk management program, determining whether the risk management process, strategy, and plan are still suitable in light of the organization's external and internal perspective, reporting on risk, progress with the risk management plan, and how well the risk management policy is being followed, and reviewing the risk management framework's effectiveness. Communication and consultation aid in understanding stakeholders' interests and concerns, ensuring that the risk management process is focused on the relevant parts, and explaining the reasoning for choices and specific risk treatment alternatives.

\subsection{Identifying Risks Using Soft Systems Methodology (SSM)}

Soft systems methodology (SSM) is a widely used methodology to analyse and solve problems in complex conditions [44]. As shown in Figure 2, this methodology consists of seven stages and organizes the way we think about complex situations so that action can be taken to improve them [45]. SSM uses "systems thinking" in a cycle of action research, learning, and reflection to help understand the various perceptions that may exist in the minds of different people involved in the situation [46]. Creating a rich picture is one of four problematic situation recognition techniques that have emerged from many successful tests and have become a common component in the SSM method [44]. Drawing rich pictures is a good way to show the relationships aiming to make sense of the system and to access key elements, structures, and perspectives in a situation [47]. The picture is much more useful than the written explanation, as it leads into a discussion on a level far greater than usual [44]. As mentioned, few studies have been conducted on the blood SC. Therefore, checking for a complete understanding of the components and connections of the BSC can be helpful. To identify the risks of a blood SC, a rich picture of this chain can provide better insights for experts. Hence, in this study, using the rich picture within the SSM approach, different sections related to the BSC are determined to identify their risks. Then 
the risks in each of the segments are identified using interview sessions and a research literature review.



Figure 2. Seven steps of SSM adopted from Wang, Liu and Mingers [45].

\subsection{Determining the Importance of Risks Using the Social Network Analysis (SNA) Approach}

At this stage, we attempt to identify the most important risks using the degree of centrality analysis in the SNA approach. Degree of centrality: the simplest definition of centrality is that the central node is the most active one and has the most connections to other nodes [48]. The degree of a node is used to describe the total relations of that node with other nodes, or the number of edges adjacent to that node [49]. In the present study, from a conceptual point of view, having a higher degree of centrality indicates a risk that is most closely linked to other risks.

In this approach, the network is usually represented as a graph consisting of links by lines and nodes by points [50]. For centrality analysis, nodes are important; they are influenced by the degree of centrality. The centrality index is a method of measuring the number of links to a node [51]. In fact, the centrality of a node indicates the importance of that node as a whole [52]. Centrality is one of the most widely used indicators in SNA and represents what entity in the network is the core or has the most power [53].

Method of collecting data in SNA: the relational data required in this research were obtained by asking the experts about the relationship of each segment's risks to each other and their relationship to the risks of other segments in a focus group meeting. In total, 11 experts were selected among the experienced managers in the Iranian BSC.

\subsection{Investigating the Relationships among Risks Using ISM}

The Interpretive Structural Modelling (ISM) methodology was first proposed to deal with complex problems. ISM is an analytical method that allows us to develop a structure of all existing relationships among the various components of a complex system [54]. The primary goal of such a model is to use experts' knowledge and expertise to analyse complex system issues and then create a multi-level structural model [55]. The ISM approach is to be used by following several well-defined procedures in the sequence listed below. Each step is important and connected to the one before it, and it cannot be skipped [56]:

1. Identification of criteria: The elements are selected based on their relevance to the problem, so the first step is to identify them. In this step, the key risks identified in the previous step are used.

2. Establishing the relation between dimensions and indicators: It expresses the relationship between variables. Such relationships can have a wide range of consequences (influencing, comparative, temporal, or neutral). 
3. Construction of the Structural Self-Interaction Matrix (SSIM) by pairwise comparison: The participants should decide on the pair relationship between the variables during this step. The relationship between two variables $i$ and $j$ is investigated, as well as the direction of the relationship. The four symbols used to indicate the direction of the $i$ and $j$ relationship are as follows:

- $\quad \mathcal{V}$ : variable $i$ leads to variable $j$.

- $\quad \mathcal{A}$ : variable $j$ leads to the variable $i$.

- $\quad \mathcal{X}$ : a bidirectional relationship (from $i$ to $j$ and from $j$ to $i$ )

- $\mathcal{O}$ : no relationship between the variables.

4. Development of a reachability matrix from SSIM and transitivity check: This step is related to building a reachability matrix. Since this is a binary matrix, the inputs $\mathcal{V}, \mathcal{A}, \mathcal{X}$, and $\mathcal{O}$ of SSIM are converted to 1 and 0 .

5. Level partition on reachability matrix: The reachability matrix is classified at different levels.

6. Development of the digraph: Elements are graphically arranged in levels and links are drawn according to the relationships shown in the reachability matrix.

7. Interaction matrix: The final digraph is transformed into a binary interaction matrix that represents all relationships with input 1.

8. Diagraph formation and its conversion: The digraph is converted to ISM and examined for conceptual inconsistency.

9. MICMAC analysis: The purpose of this analysis is to identify and analyse the driving and dependence power of variables. So, the variables are divided into four categories of autonomous, dependent, linkage and independent drivers in terms of the driving and dependence power.

\subsection{Strategies for Threats}

Various strategies have been proposed in the literature for risk treatment and response, most of which have emphasized risk mitigation $[57,58]$. Here are five common types of treatments [59]:

I. Risk acceptance: This strategy means that because of, for example, high costs, risk is accepted, and nothing is done about it [60].

II. Risk avoidance: This strategy seeks to eliminate the types of events and root causes that trigger risk [61].

III. Risk transfer: This strategy means delegating responsibility to another group. They are especially suitable for disruption risks such as natural disasters, which have a low probability and high impact (Zhen et al., 2016).

IV. IRisk sharing: This strategy means sharing some or all of the risks with another party, which is usually done through contracting by other companies [62].

V. $\quad$ Risk mitigation: This strategy seeks to reduce risks to an acceptable level [63].

\section{Practical Implementation}

The research methodology states that this study uses SSM, SNA, and ISM to identify the relevance of and correlations between risks. As shown in Figure 1, this section is broken down into three sections. The main aim of this section is to assess the proposed model using a case study. Therefore, some health centres, which are highly exposed to risks, are analysed. In addition, a comprehensive sensitivity analysis of some factors is conducted to provide insights into how the performance of the system can be enhanced.

\subsection{Identifying the Risks in the BSC Using SSM}

SSM is first used to identify the SC and the set of relationships it has with other departments, as shown in Figure 1. In fact, a detailed picture is used to aid in risk identification. So, once the sections related to the blood SC are determined, the risks in each of these sections are determined. For example, the relationship between the government and the 
BSC is determined using the rich picture in Figure 3. Following that, the risks associated with each sector are identified.

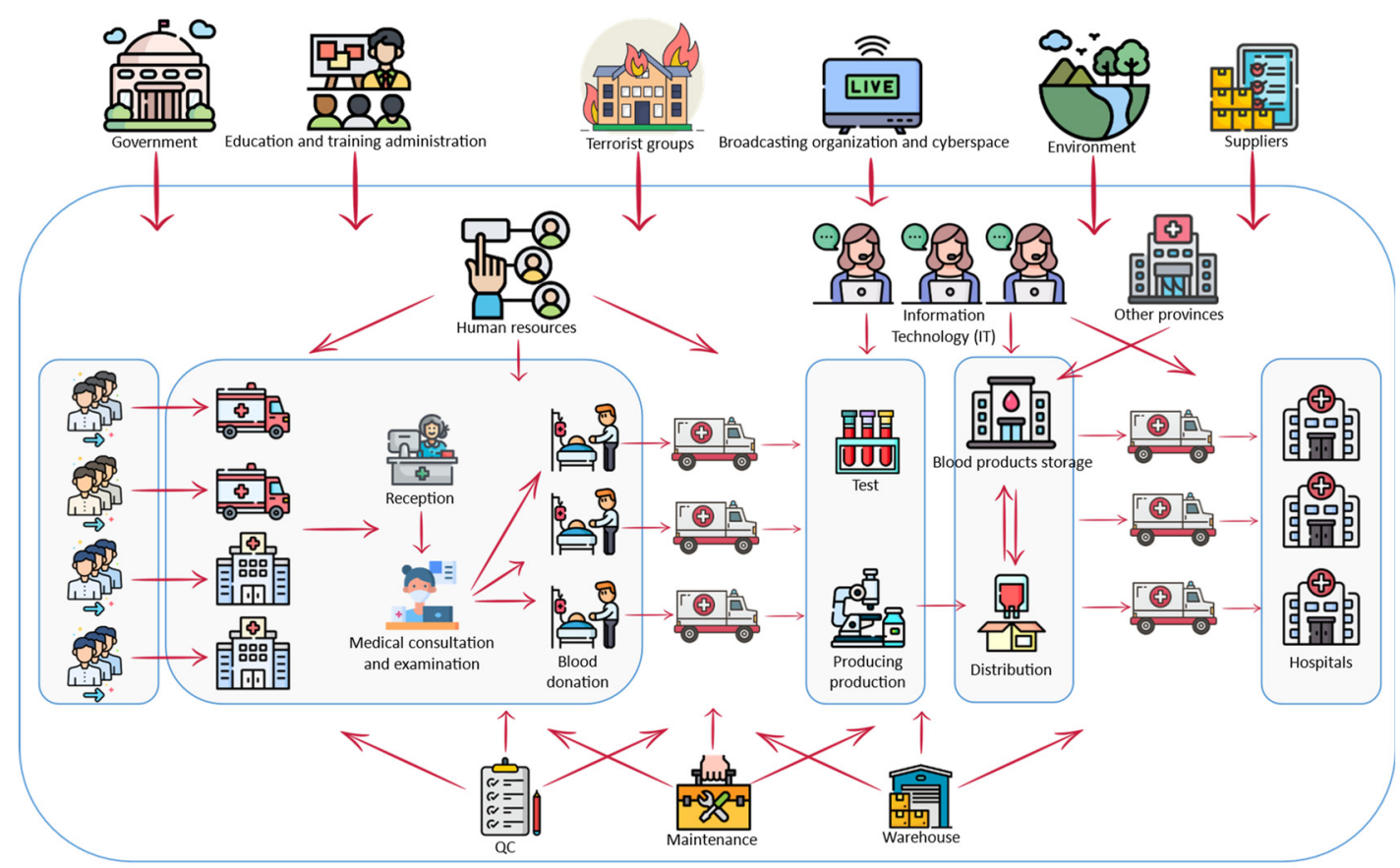

Figure 3. The rich picture of the BSC.

The Blood SCRs are categorized according to the identified segments of SSM. As shown in Figure 3, firstly, the relevant sections in the BSC have been drawn to recognize the SC completely, then the risks of each segment have been identified using expert opinions. Table 2 indicates the identified segments for a total of 102 risks.

\subsection{Identifying the Important Risks by Using SNA}

The importance of the previously identified risks will be determined using the SNA method at this stage. UCINET and NetDraw software were used for this purpose. Experts determined whether or not any identified risk was related to each other in order to collect relational data. As a result, the risk communication matrix was entered into the UCINET software as an input, and the relationship network was plotted in the NetDraw software. The two software facilities were then used to calculate and analyse various values of centrality in the network. Figure 4 depicts a graph of NetDraw software's degree of centrality. The larger the size of each node, the greater the degree of centrality of that node.

The degree of centrality in the network of blood SCRs indicates how each risk is related to other risks. The higher the centrality index, the more closely related that risk is to other risks. The risks were then sorted according to their centrality index using the $\mathrm{Q}$ score. The risks in the upper quartile are the most significant and have the highest degree of centrality. In other words, because of their relevance to other risks, these risks are considered key risks in the network and are thus chosen for further analysis and evaluation. For a better understanding of Figure 4, Table 3 is presented to show the degree of centrality of all risks. 
Table 2. BSC risks.

\begin{tabular}{|c|c|c|}
\hline Segments & Code & Risks \\
\hline \multirow{7}{*}{ Reception } & R1 & An insufficient estimate of the amount needed to collect \\
\hline & R2 & Getting inadequate or incorrect clinical information in the application form \\
\hline & R3 & Unavailability of some blood donation centres \\
\hline & R4 & Decreased blood donor satisfaction \\
\hline & R5 & Software problems \\
\hline & R6 & Differences in the quality of products produced by different blood transfusion centres \\
\hline & R7 & Congestion and rush to donate blood \\
\hline \multirow{2}{*}{ Medical consultation and examination } & R8 & Failure of donor screening \\
\hline & R9 & Gathering incorrect information from a donor \\
\hline \multirow{7}{*}{ Blood donation } & R10 & Lack of quality and safety during blood donation \\
\hline & R11 & Equipment failure \\
\hline & R12 & Mismatch \\
\hline & R13 & Wastes and losses \\
\hline & R14 & Non-calibrated equipment \\
\hline & R15 & The temperature change of the blood bags \\
\hline & R16 & Late delivery \\
\hline \multirow{3}{*}{ Other provinces } & R17 & Decreased blood quality during transportation \\
\hline & R18 & Delay in receiving blood \\
\hline & R19 & Getting poor quality blood \\
\hline Maintenance & R20 & Failure to perform preventive maintenance \\
\hline \multirow{6}{*}{ Producing production } & R21 & Temperature changes \\
\hline & R22 & Equipment failure \\
\hline & R23 & Non-calibrated equipment \\
\hline & R24 & Software and system problems \\
\hline & R25 & Sources likely to be compromised following an autoclave explosion \\
\hline & R26 & Expiration of products \\
\hline \multirow{8}{*}{ Test } & R27 & Error in confirming the blood group \\
\hline & R28 & Undetectable new viruses \\
\hline & R29 & Incorrect confirmation of the sample \\
\hline & R30 & Unsafe disposal of positive units \\
\hline & R31 & Error in data entry \\
\hline & R32 & Temperature changes \\
\hline & R33 & Non-calibrated equipment \\
\hline & R34 & Equipment failure \\
\hline \multirow{5}{*}{ Blood products storage } & R35 & Improper blood inventory level \\
\hline & R36 & Shortage of emergency storage units \\
\hline & R37 & Insecure disposal of expired units \\
\hline & R38 & Blood rotting \\
\hline & R39 & Expiration of blood products \\
\hline
\end{tabular}


Table 2. Cont.

\begin{tabular}{|c|c|c|}
\hline Segments & Code & Risks \\
\hline \multirow{8}{*}{ Distribution } & R40 & An insufficient response to the hospital demand \\
\hline & R41 & Delivering wrong blood bag \\
\hline & R42 & Improper blood supply (life expectancy) \\
\hline & R43 & Improper allocation of blood to different centres (in terms of units) \\
\hline & R44 & Non-standard packaging on delivery \\
\hline & R45 & Delays in shipping \\
\hline & R46 & Equipment failure \\
\hline & R47 & Decreased blood quality during transportation \\
\hline \multirow{3}{*}{ Warehouse } & R48 & Product corruption \\
\hline & R49 & Lack of materials and equipment (such as kits and bags) \\
\hline & R50 & Excessive items \\
\hline \multirow{9}{*}{ Hospitals } & R51 & A mistake in blood compatibility test \\
\hline & R52 & Delay in the use of allocated blood bags \\
\hline & R53 & Waiting for the blood reserved by doctors \\
\hline & R54 & Insufficient blood inventory level \\
\hline & R55 & Improper disposal of expired units or wastes \\
\hline & R56 & Inappropriate assessment of the amount of blood required before surgery \\
\hline & R57 & Blood rotting \\
\hline & R58 & Temperature changes \\
\hline & R59 & Side effects of blood transfusion \\
\hline \multirow{7}{*}{ Government } & R60 & Cumbersome rules (such as customs rules) \\
\hline & R61 & Lack of proper budget allocation \\
\hline & R62 & Economic and political effects of sanctions \\
\hline & R63 & changes in the exchange rate \\
\hline & R64 & Inflation \\
\hline & R65 & Energy rate changes \\
\hline & R66 & Financial crises \\
\hline \multirow{5}{*}{ Suppliers } & R67 & Selection of inappropriate suppliers \\
\hline & R68 & Delay in dispatch \\
\hline & R69 & Purchase of inappropriate equipment \\
\hline & R70 & Cut-off relationships with suppliers \\
\hline & R71 & Inappropriate contracts \\
\hline Education and training administration & R72 & Inappropriate public education \\
\hline Broadcasting organization and cyberspace & R73 & Inaccurate and false information and false excitement \\
\hline Certificate companies & R74 & Improper implementation of standards \\
\hline \multirow{6}{*}{ QC } & R75 & Error in checking tests \\
\hline & R76 & Inadequate quality control of materials \\
\hline & R77 & Improper quality control of products \\
\hline & R78 & Failure to identify discrepancies in the audit \\
\hline & R79 & Not paying attention to the documentation revision \\
\hline & $\mathrm{R} 80$ & Not paying attention to the process of quality assurance system development \\
\hline
\end{tabular}


Table 2. Cont.

\begin{tabular}{|c|c|c|}
\hline \multirow[t]{2}{*}{ Segments } & Code & Risks \\
\hline & R81 & Incorrect conduct of validation studies \\
\hline \multirow{4}{*}{ (IT) } & R82 & Unauthorized access to organizational information \\
\hline & R83 & Cyber-attacks and hacking \\
\hline & R84 & Failure to server data recovery \\
\hline & R85 & Lack of data transfer between different systems \\
\hline \multirow{6}{*}{ Environment } & R86 & Power outage \\
\hline & R87 & Earthquake \\
\hline & R88 & Fire \\
\hline & R89 & Contagious events \\
\hline & R90 & Severe climate change \\
\hline & R91 & Emerging diseases \\
\hline \multirow{2}{*}{ Society } & R92 & Changing culture and lifestyle \\
\hline & R93 & Street chaos \\
\hline \multirow{2}{*}{ Terrorist groups } & R94 & Terrorist attacks \\
\hline & R95 & War \\
\hline \multirow{7}{*}{ Human resources } & R96 & Safety negligence \\
\hline & R97 & Incompatibility of human resources with the goals of the organization \\
\hline & R98 & Low productivity of the employees \\
\hline & R99 & Strike \\
\hline & R100 & Not paying attention to standards and validations \\
\hline & R101 & Lack of succession \\
\hline & R102 & Not saving the knowledge of human resources \\
\hline
\end{tabular}

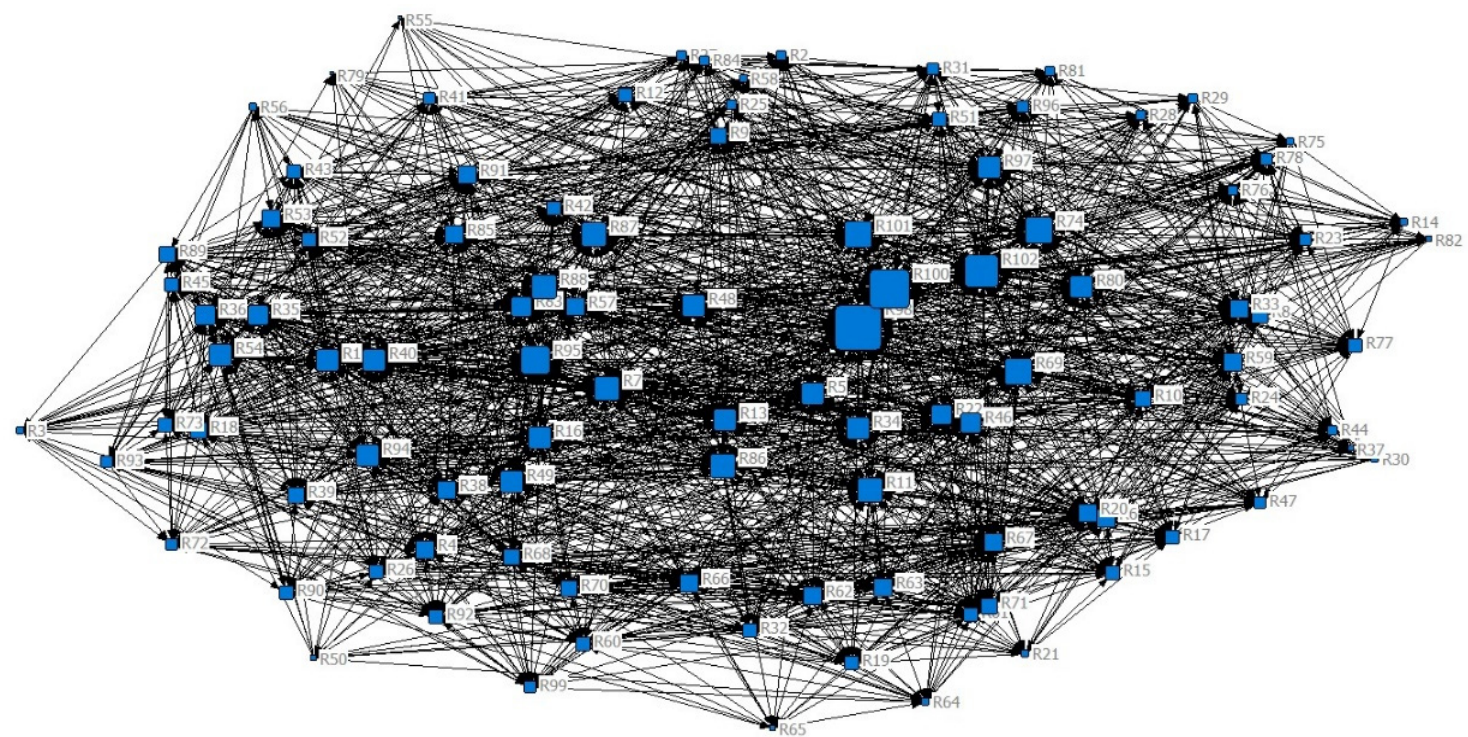

Figure 4. Relation among risks according to the degree of centrality. 
Table 3. Importance of the identified risks in terms of the degree of centrality.

\begin{tabular}{cccccccccccc}
\hline Risk & Degree & Risk & Degree & Risk & Degree & Risk & Degree & Risk & Degree & Risk & Degree \\
\hline R1 & 37 & R18 & 21 & R35 & 36 & R52 & 12 & R69 & 34 & R86 & 34 \\
R2 & 19 & R19 & 9 & R36 & 34 & R53 & 33 & R70 & 29 & R87 & 38 \\
R3 & 8 & R20 & 37 & R37 & 12 & R54 & 33 & R71 & 31 & R88 & 31 \\
R4 & 27 & R21 & 16 & R38 & 32 & R55 & 10 & R72 & 17 & R89 & 30 \\
R5 & 39 & R22 & 31 & R39 & 32 & R56 & 20 & R73 & 28 & R90 & 22 \\
R6 & 30 & R23 & 19 & R40 & 37 & R57 & 26 & R74 & 13 & R91 & 30 \\
R7 & 39 & R24 & 5 & R41 & 22 & R58 & 14 & R75 & 11 & R92 & 28 \\
R8 & 29 & R25 & 19 & R42 & 25 & R59 & 32 & R76 & 20 & R93 & 16 \\
R9 & 31 & R26 & 23 & R43 & 27 & R60 & 25 & R77 & 18 & R94 & 26 \\
R10 & 25 & R27 & 23 & R44 & 13 & R61 & 29 & R78 & 11 & R95 & 33 \\
R11 & 38 & R28 & 23 & R45 & 19 & R62 & 36 & R79 & 7 & R96 & 18 \\
R12 & 29 & R29 & 23 & R46 & 33 & R63 & 36 & R80 & 9 & R97 & 12 \\
R13 & 39 & R30 & 17 & R47 & 14 & R64 & 17 & R81 & 10 & R98 & 51 \\
R14 & 13 & R31 & 24 & R48 & 30 & R65 & 10 & R82 & 15 & R99 & 8 \\
R15 & 26 & R32 & 24 & R49 & 37 & R66 & 30 & R83 & 33 & R100 & 38 \\
R16 & 37 & R33 & 31 & R50 & 14 & R67 & 37 & R84 & 15 & R101 & 31 \\
R17 & 16 & R34 & 30 & R51 & 28 & R68 & 30 & R85 & 26 & R102 & 38 \\
\hline
\end{tabular}

As shown in Figure 4 and Table 3, the risk of low employee productivity has the highest degree of centrality; that means this risk can affect or be affected by many other risks.

\subsection{Determining the Relationship among Risks}

On the most important risks identified, a more detailed analysis of relationships and classification is required. These risks were incorporated into the structural self-interaction matrix. To accomplish this, a questionnaire with 17 risks was produced, and experts were asked to identify the relationships between the risks. The experts completed the structural self-interaction matrix by utilising the four conceptual relationship modes (Table 4).

Table 4. Structural self-interaction matrix.

\begin{tabular}{|c|c|c|c|c|c|c|c|c|c|c|c|c|c|c|c|c|c|}
\hline & R98 & R7 & R100 & R102 & R67 & R13 & $\mathrm{R} 40$ & R11 & R35 & R62 & R49 & R1 & R5 & R63 & R16 & R20 & R87 \\
\hline R98 & & $x$ & $x$ & $x$ & $\mathrm{~V}$ & $\mathrm{~V}$ & $\mathrm{~V}$ & V & $\mathrm{O}$ & $\mathrm{O}$ & $\mathrm{V}$ & $\mathrm{V}$ & $x$ & $\mathrm{O}$ & $\mathrm{V}$ & $\mathrm{V}$ & A \\
\hline R7 & $X$ & & V & A & $\mathrm{O}$ & $x$ & $\mathrm{O}$ & V & $\mathrm{O}$ & $\mathrm{O}$ & $x$ & $\mathrm{O}$ & $x$ & $\mathrm{O}$ & $\mathrm{V}$ & $\mathrm{O}$ & A \\
\hline R100 & $x$ & A & & V & V & $\mathrm{V}$ & $\mathrm{O}$ & V & V & A & $\mathrm{V}$ & $\mathrm{V}$ & $x$ & $\mathrm{O}$ & $\mathrm{V}$ & $\mathrm{V}$ & A \\
\hline R102 & $x$ & $\mathrm{~V}$ & A & & V & V & $\mathrm{V}$ & V & V & $\mathrm{O}$ & $\mathrm{V}$ & $\mathrm{V}$ & $x$ & $\mathrm{O}$ & $\mathrm{V}$ & A & A \\
\hline R67 & A & $\mathrm{O}$ & A & A & & $\mathrm{V}$ & $\mathrm{V}$ & V & V & A & $\mathrm{V}$ & $\mathrm{V}$ & $\mathrm{V}$ & A & $\mathrm{O}$ & $\mathrm{V}$ & $\mathrm{O}$ \\
\hline R13 & A & $x$ & A & A & A & & $\mathrm{V}$ & V & V & A & $\mathrm{O}$ & $\mathrm{O}$ & $\mathrm{O}$ & A & $\mathrm{V}$ & A & A \\
\hline R40 & A & $\mathrm{O}$ & $\mathrm{O}$ & A & A & A & & A & A & $\mathrm{O}$ & A & A & A & $\mathrm{O}$ & A & A & A \\
\hline R11 & A & A & A & A & A & A & $\mathrm{V}$ & & V & A & $\mathrm{V}$ & $\mathrm{O}$ & 0 & A & $\mathrm{V}$ & A & A \\
\hline R35 & $\mathrm{O}$ & $\mathrm{O}$ & A & A & A & A & $\mathrm{V}$ & A & & $\mathrm{O}$ & A & A & A & $\mathrm{O}$ & A & $\mathrm{A}$ & A \\
\hline R62 & $\mathrm{O}$ & $\mathrm{O}$ & V & $\mathrm{O}$ & V & $\mathrm{V}$ & $\mathrm{O}$ & V & $\mathrm{O}$ & & $\mathrm{V}$ & $\mathrm{O}$ & $\mathrm{O}$ & $\mathrm{V}$ & $\mathrm{O}$ & $\mathrm{V}$ & $\mathrm{O}$ \\
\hline R49 & A & $x$ & A & A & A & $\mathrm{O}$ & $\mathrm{V}$ & A & V & A & & $\mathrm{O}$ & $\mathrm{O}$ & A & $\mathrm{O}$ & A & A \\
\hline R1 & A & $\mathrm{O}$ & A & A & A & $\mathrm{O}$ & $\mathrm{V}$ & $\mathrm{O}$ & V & $\mathrm{O}$ & $\mathrm{O}$ & & A & $\mathrm{O}$ & $\mathrm{O}$ & $\mathrm{O}$ & $\mathrm{O}$ \\
\hline R5 & $x$ & $x$ & $x$ & $x$ & A & $\mathrm{O}$ & $\mathrm{V}$ & 0 & V & $\mathrm{O}$ & $\mathrm{O}$ & $\mathrm{V}$ & & $\mathrm{O}$ & $\mathrm{O}$ & A & $\mathrm{O}$ \\
\hline R63 & $\mathrm{O}$ & $\mathrm{O}$ & $\mathrm{O}$ & $\mathrm{O}$ & V & $\mathrm{V}$ & $\mathrm{O}$ & V & $\mathrm{O}$ & A & $\mathrm{V}$ & $\mathrm{O}$ & $\mathrm{O}$ & & $\mathrm{O}$ & $\mathrm{V}$ & $\mathrm{O}$ \\
\hline R16 & A & A & A & A & $\mathrm{O}$ & A & $\mathrm{V}$ & A & $\mathrm{V}$ & $\mathrm{O}$ & $\mathrm{O}$ & $\mathrm{O}$ & $\mathrm{O}$ & $\mathrm{O}$ & & $\mathrm{O}$ & A \\
\hline R20 & A & $\mathrm{O}$ & A & $\mathrm{V}$ & A & $\mathrm{V}$ & $\mathrm{V}$ & V & V & A & $\mathrm{V}$ & $\mathrm{O}$ & $\mathrm{V}$ & A & $\mathrm{O}$ & & A \\
\hline R87 & $\mathrm{V}$ & $\mathrm{V}$ & V & V & $\mathrm{O}$ & $\mathrm{V}$ & $\mathrm{V}$ & V & V & $\mathrm{O}$ & $\mathrm{V}$ & $\mathrm{O}$ & $\mathrm{O}$ & $\mathrm{O}$ & $\mathrm{V}$ & $\mathrm{V}$ & \\
\hline
\end{tabular}

By converting the SSIM into a binary matrix, the initial reachability matrix was obtained. Following the formation of the initial reachability matrix, the final reachability matrix was created in the same manner as shown in Table 5. 
Table 5. Final reachability matrix.

\begin{tabular}{|c|c|c|c|c|c|c|c|c|c|c|c|c|c|c|c|c|c|}
\hline & R98 & R7 & R100 & R102 & R67 & R13 & $\mathrm{R} 40$ & R11 & R35 & R62 & R49 & R1 & R5 & R63 & R16 & R20 & R87 \\
\hline R98 & 1 & 1 & 1 & 1 & 1 & 1 & 1 & 1 & 1 & 0 & 1 & 1 & 1 & 0 & 1 & 1 & 0 \\
\hline R7 & 1 & 1 & 1 & 1 & 1 & 1 & 1 & 1 & 1 & 0 & 1 & 1 & 1 & 0 & 1 & 1 & 0 \\
\hline R100 & 1 & 1 & 1 & 1 & 1 & 1 & 1 & 1 & 1 & 0 & 1 & 1 & 1 & 0 & 1 & 1 & 0 \\
\hline R102 & 1 & 1 & 1 & 1 & 1 & 1 & 1 & 1 & 1 & 0 & 1 & 1 & 1 & 0 & 1 & 1 & 0 \\
\hline $\mathrm{R} 67$ & 1 & 1 & 1 & 1 & 1 & 1 & 1 & 1 & 1 & 0 & 1 & 1 & 1 & 0 & 1 & 1 & 0 \\
\hline R13 & 1 & 1 & 1 & 1 & 1 & 1 & 1 & 1 & 1 & 0 & 1 & 1 & 1 & 0 & 1 & 1 & 0 \\
\hline $\mathrm{R} 40$ & 0 & 0 & 0 & 0 & 0 & 0 & 1 & 0 & 0 & 0 & 0 & 0 & 0 & 0 & 0 & 0 & 0 \\
\hline R11 & 1 & 1 & 1 & 1 & 1 & 1 & 1 & 1 & 1 & 0 & 1 & 1 & 1 & 0 & 1 & 1 & 0 \\
\hline R35 & 0 & 0 & 0 & 0 & 0 & 0 & 1 & 0 & 1 & 0 & 0 & 0 & 0 & 0 & 0 & 0 & 0 \\
\hline R62 & 1 & 1 & 1 & 1 & 1 & 1 & 1 & 1 & 1 & 1 & 1 & 1 & 1 & 1 & 1 & 1 & 0 \\
\hline R49 & 1 & 1 & 1 & 1 & 1 & 1 & 1 & 1 & 1 & 0 & 1 & 1 & 1 & 0 & 1 & 1 & 0 \\
\hline $\mathrm{R} 1$ & 0 & 0 & 0 & 0 & 0 & 0 & 1 & 0 & 1 & 0 & 0 & 1 & 0 & 0 & 0 & 0 & 0 \\
\hline R5 & 1 & 1 & 1 & 1 & 1 & 1 & 1 & 1 & 1 & 0 & 1 & 1 & 1 & 0 & 1 & 1 & 0 \\
\hline R63 & 1 & 1 & 1 & 1 & 1 & 1 & 1 & 1 & 1 & 0 & 1 & 1 & 1 & 1 & 1 & 1 & 0 \\
\hline R16 & 0 & 0 & 0 & 0 & 0 & 0 & 1 & 0 & 1 & 0 & 0 & 0 & 0 & 0 & 1 & 0 & 0 \\
\hline R20 & 1 & 1 & 1 & 1 & 1 & 1 & 1 & 1 & 1 & 0 & 1 & 1 & 1 & 0 & 1 & 1 & 0 \\
\hline R87 & 1 & 1 & 1 & 1 & 1 & 1 & 1 & 1 & 1 & 0 & 1 & 1 & 1 & 0 & 1 & 1 & 1 \\
\hline
\end{tabular}

The final reachability matrix must be categorized into different levels. Therefore, in this study, according to the levels of risks and the final reachability matrix, the final model was drawn, which consisted of six levels. It is to be noted that, as shown in Figure 5, higherlevel risks are less effective and more likely to be affected by other risks. For example, insufficient response to the hospital demand (R40) is at its highest level, so lower risk levels are more likely to be affected. In addition, sanctions' economic and political effects are at the lowest level, indicating that they can affect other risks; hence, some approaches must be considered to address it.

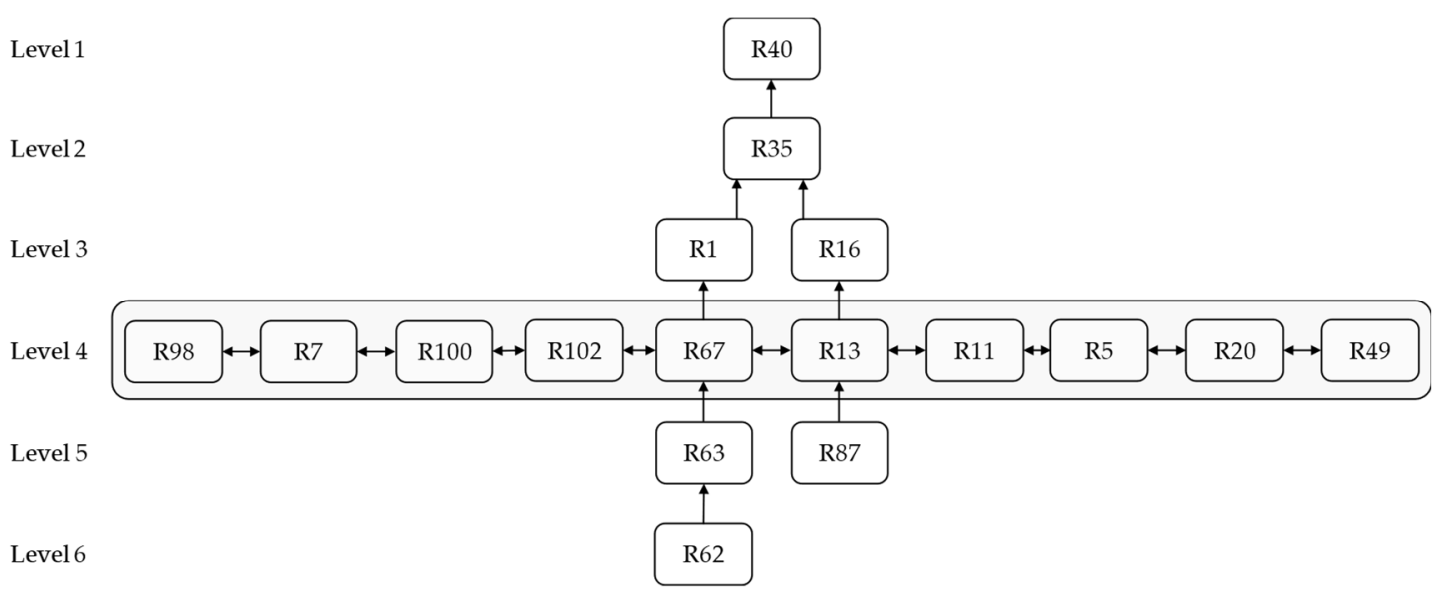

Figure 5. ISM-based model of BSC risks.

\subsection{MICMAC Analysis}

At this stage, using the MICMAC diagram and after determining the driving and dependence power of the risks, all key risks in the BSC can be organized into one of the four categories. The first group includes autonomous risks that are somewhat separate from other risks and have little relevance; there was no autonomous risk in this study. The second group belongs to dependent risks that have weak influence but high dependency. According to Figure 6, the dependent risks include an insufficient estimate of the amount needed to collect (R1), late delivery (R16), improper blood inventory level (R35), and insufficient response to hospital demand (R40) as the most affected by other risks. In other words, there are many factors involved in creating these risks, which are less likely to pose other risks. The third group consists of linkage risks with high driving power and high dependency. 
This group includes the risks of software problems (R5), equipment failure (R11), wastes and losses (R13), failure to perform preventive maintenance (R20), lack of materials and equipment (such as kits and bags) (R49), not paying attention to standards and validations (R100), reduction in employee productivity (R98), and selection of inappropriate suppliers (R67). The last group includes independent risks such as economic and political effects of sanctions (R62), changes in the exchange rate (R63) and earthquakes (R87). These risks have high driving power and low dependency. Risks with high driving power are called key risks, which fall into one of the two groups of independent risks or linkage risks. In fact, any changes to these risks can change other risks.

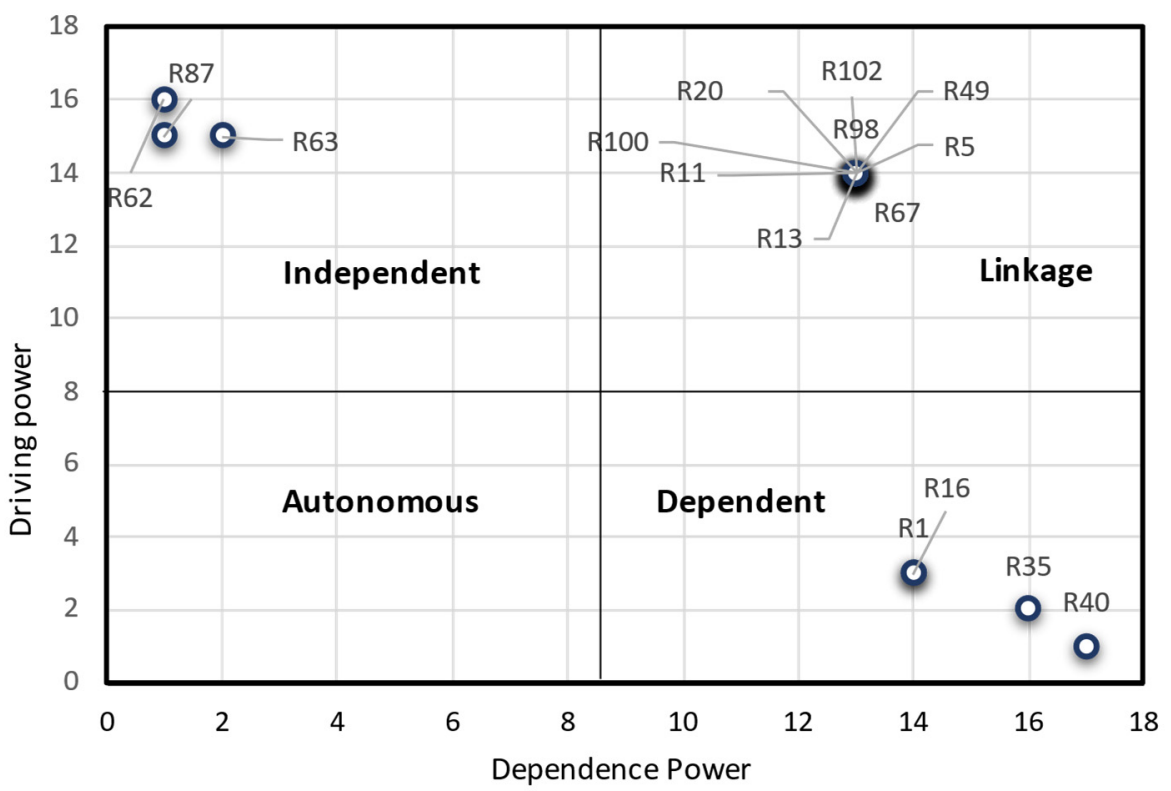

Figure 6. MICMAC analysis.

\section{Discussion and Conclusions}

\subsection{Discussion}

BSCs are exposed to a variety of risks in many health systems, and their neglect can result in a slew of complications. SCRM, which has grown in popularity over the last few years, can assist managers in better preparing for future events by identifying and analysing risks within the SC. Due to the importance of this research area, this research proposed a new systemic approach (SSI) for identifying and analysing SCRs. By first taking a holistic view and conducting a more comprehensive study of the BSC and its components, as well as by utilising a rich picture within SSM, risks associated with each segment were identified throughout the SC with the assistance of experts and previous articles. Then, as previously stated, due to the critical nature of relationships in evaluating SCRs and the large number of identified risks, SNA was used to ascertain the relationships among the identified risks and to select the most significant ones. Finally, the ISM approach was used to examine the levelling and establish bilateral relationships between the key risks.

By drawing the rich picture of the Iranian blood SC, the whole blood SCRs could be better identified, and 102 risks were extracted. An analysis of risk relationships was conducted utilising SNA and the input of industry experts, and then the most important risks were chosen. Risks include low productivity of employees, earthquakes, changes in the exchange rates, an insufficient response to hospital demand, and late delivery of the blood bags, to mention but a few. In fact, given the high relation of these risks, managers should be particularly concerned with identifying appropriate strategies for mitigating them. Then, ISM and MICMAC analyses were conducted for the key selected risks. Risks such as the economic and political effects of sanctions, changes in the exchange rate and earthquakes have high driving power and low dependency. Management should consider 
these risks because of their high impact on other risks, as determined by the MICMAC analysis report. Due to the lack of management control over these risks, managers need to enact policies specific to dealing with them. Particularly, an earthquake is a disruption event and is unpredictable, so special strategies such as flexibility and agility in the transportation systems and redundancy in inventory and suppliers are required to make the SC resilient. Another important point regarding the management of risks in health systems is that these risks are not medical, so the top managers of the BSC must also take general management courses, particularly risk management. Higher levels of risk include, for example, late delivery, incorrect blood inventory levels and inadequate estimations of the amount needed to collect blood. Blood-related risks, which can be influenced by other risks, appear in the dependent group. Because of their importance and direct effects on human life, they must be regarded in particular.

Risks such as earthquakes ( $R$ 87), exchange rate fluctuations ( $R$ 63), and the political consequences of sanctions ( $R$ 62) are among the risks identified as independent variables in the MICMAC matrix. There are two critical points to consider regarding these risks. To begin, these are the most effective and least dependent risks. Second, these risks are out of the organization's control and are frequently referred to as disruption risks. Risk sharing or risk transfer may be the appropriate strategy for the organisation to pursue. Additionally, without a doubt, managers should consider making supply chains resilient, given the critical nature of resilience in today's world. Naturally, in the event of an earthquake, numerous articles have been reviewed to strengthen the blood supply chain's resilience. For the other two risks, namely the political consequences of sanctions and the exchange rate, focusing on domestic production may be an advisable policy. On the other hand, risks such as late delivery (R16), insufficient blood inventory (R35), and insufficient response to hospital demand (R40) are all influenced by other risks. As is well known, these risks are classified as operational risks, and risk mitigation strategies are typically used to mitigate them. Of course, depending on the budget available to the supply chain, an acceptable level of shortages or delays can be tolerated, and determining this level of tolerance can be a worthwhile project for supply chain managers.

\subsection{Managerial and Practical Insights}

In many countries, particularly in developing countries, health-care systems face numerous challenges due to a lack of adequate health-management systems and procedures. This is especially true for the blood supply chain and other vital products. It is costly for countries to replace their ageing systems and infrastructure in health systems, so they should plan for unexpected events such as natural disasters and an exponential rise in demand. This demonstrates that, while many risks in the blood supply chain are rare, preparing current health systems is critical. As a result, this research can assist some organisations, such as the Iranian Blood Transfusion Organization, in developing a central system to manage risks associated with the blood supply chain. To help with risk management, the proposed approach can take into account a wide range of realistic factors. Furthermore, this research may benefit the World Health Organization (WHO), which works to promote health, keep the world safe, and assist the vulnerable on a global scale. As previously stated, while many management techniques are now aimed at improving health systems, these approaches are unprepared to deal with risks associated with the blood supply chain. Current risk management techniques emphasise increasing the capacity to respond to challenges, but many risks in blood supply systems cannot be addressed through capacity expansion or the establishment of new infrastructure.

\subsection{Limitations and Future Directions}

The constraints of time and resources affect every research study. Even though each study has its own set of limitations, they can still lead to new discoveries and ideas. The conclusions of this study are the result of interactions between participants and the researcher, as well as the researcher's observations and interpretations based on some 
novel approaches. It might be claimed that the qualitative findings of this study should be changed to be generalizable in light of the new situation. Another limitation of this study is related to its boundary. Only those directly participating in the BSC process were chosen. The study did not include all of the critical external stakeholders who are important in improving hospital service delivery. Furthermore, since the purpose of the present study was to examine the relationship among risks and also structure them, the mutual effects of risks were not considered in the SNA approach; otherwise, employing an alternative approach is suggested. The use of MCDM methods after SNA rather than ISM can determine the appropriate risk rankings, so evaluating proper strategies for important risks can be done as well. In this study, there was no discussion of suitable strategies for risk reduction, and further research can determine the appropriate strategies for each of the key risks. Future research can also address BSC disruptions and resiliency strategies.

Author Contributions: Conceptualization, A.S., M.Z. and A.A.; methodology, A.S.; software, A.S.; validation, A.S., M.Z. and S.M.K.; formal analysis, A.S.; investigation, A.S.; resources, A.S.; data curation, A.S.; writing — original draft preparation, A.S. and S.M.K.; writing-review and editing, A.S., M.Y. and S.M.K.; visualization, M.Y.; supervision, A.A. and M.Z.; project administration, A.S.; funding acquisition, M.Y. All authors have read and agreed to the published version of the manuscript.

Funding: This research received no external funding.

Institutional Review Board Statement: Not applicable.

Informed Consent Statement: Not applicable.

Data Availability Statement: The data used in the study is available with the authors and can be shared upon reasonable requests.

Conflicts of Interest: The authors declare no conflict of interest.

\section{References}

1. Hashemi Petrudi, S.H.; Tavana, M.; Abdi, M. A comprehensive framework for analyzing challenges in humanitarian supply chain management: A case study of the Iranian Red Crescent Society. Int. J. Disaster Risk Reduct. 2020, 42, 101340. [CrossRef]

2. Nili, M.; Seyedhosseini, S.M.; Jabalameli, M.S.; Dehghani, E. A multi-objective optimization model to sustainable closed-loop solar photovoltaic supply chain network design: A case study in Iran. Renew. Sustain. Energy Rev. 2021, 150, 111428. [CrossRef]

3. Salehi, R.; Ali Asaadi, M.; Haji Rahimi, M.; Mehrabi, A. The information technology barriers in supply chain of sugarcane in Khuzestan province, Iran: A combined ANP-DEMATEL approach. Inf. Process. Agric. 2021, 8, 458-468. [CrossRef]

4. Alam, S.T.; Ahmed, S.; Ali, S.M.; Sarker, S.; Kabir, G.; ul-Islam, A. Challenges to COVID-19 vaccine supply chain: Implications for sustainable development goals. Int. J. Prod. Econ. 2021, 239, 108193. [CrossRef]

5. Kumar, S.; Barua, M.K. A modeling framework and analysis of challenges faced by the Indian petroleum supply chain. Energy 2022, 239, 122299. [CrossRef]

6. Habibi Rad, M.; Mojtahedi, M.; Ostwald, M.J. The Integration of Lean and Resilience Paradigms: A Systematic Review Identifying Current and Future Research Directions. Sustainability 2021, 13, 8893. [CrossRef]

7. Hendricks, K.B.; Singhal, V.R. Association Between Supply Chain Glitches and Operating Performance. Manag. Sci. 2005, 51, 695-711. [CrossRef]

8. de Bakker, K.; Boonstra, A.; Wortmann, H. Does risk management contribute to IT project success? A meta-analysis of empirical evidence. Int. J. Proj. Manag. 2010, 28, 493-503. [CrossRef]

9. Thun, J.-H.; Hoenig, D. An empirical analysis of supply chain risk management in the German automotive industry. Int. J. Prod. Econ. 2011, 131, 242-249. [CrossRef]

10. Khorshidvand, B.; Soleimani, H.; Sibdari, S.; Mehdi Seyyed Esfahani, M. A hybrid modeling approach for green and sustainable closed-loop supply chain considering price, advertisement and uncertain demands. Comput. Ind. Eng. 2021, 157, 107326. [CrossRef]

11. Habibi Rad, M.; Mojtahedi, M.; Ostwald, M.J. Industry 4.0, Disaster Risk Management and Infrastructure Resilience: A Systematic Review and Bibliometric Analysis. Buildings 2021, 11, 411. [CrossRef]

12. Najafi-Tavani, S.; Sharifi, H.; Naudé, P.; Parvizi-Omran, E. The impact of alternative financial supply chain management practices on supply risk: A relationship quality and buyer relative power perspective. Ind. Mark. Manag. 2022, 100, 112-126. [CrossRef]

13. Nimmy, S.F.; Hussain, O.K.; Chakrabortty, R.K.; Hussain, F.K.; Saberi, M. Explainability in supply chain operational risk management: A systematic literature review. Knowl. -Based Syst. 2022, 235, 107587. [CrossRef]

14. de Oliveira, U.R.; Muniz, M.d.A.; Anaia, L.A.; Rocha, H.M. Medication supply chain risk management for a brazilian home care provider: A business sustainability study. Clean. Logist. Supply Chain. 2022, 3, 100018. [CrossRef] 
15. Yazdani, M.; Mojtahedi, M.; Loosemore, M.; Sanderson, D.; Dixit, V. Hospital evacuation modelling: A critical literature review on current knowledge and research gaps. Int. J. Disaster Risk Reduct. 2021, 66, 102627. [CrossRef]

16. Aghapour, A.H.; Yazdani, M.; Jolai, F.; Mojtahedi, M. Capacity planning and reconfiguration for disaster-resilient health infrastructure. J. Build. Eng. 2019, 26, 100853. [CrossRef]

17. Mirmozaffari, M.; Shadkam, E.; Khalili, S.M.; Yazdani, M. Developing a Novel Integrated Generalised Data Envelopment Analysis (DEA) to Evaluate Hospitals Providing Stroke Care Services. Bioengineering 2021, 8, 207. [CrossRef]

18. Abbasi, B.; Babaei, T.; Hosseinifard, Z.; Smith-Miles, K.; Dehghani, M. Predicting solutions of large-scale optimization problems via machine learning: A case study in blood supply chain management. Comput. Oper. Res. 2020, 119, 104941. [CrossRef]

19. Dehghani, M.; Abbasi, B.; Oliveira, F. Proactive transshipment in the blood supply chain: A stochastic programming approach. Omega 2021, 98, 102112. [CrossRef]

20. Liu, H.-C. FMEA using cluster analysis and prospect theory and its application to blood transfusion. In Improved FMEA Methods for Proactive Healthcare Risk Analysis; Springer: Berlin/Heidelberg, Germany, 2019; pp. 73-96.

21. Rafter, N.; Hickey, A.; Condell, S.; Conroy, R.; O'connor, P.; Vaughan, D.; Williams, D. Adverse events in healthcare: Learning from mistakes. QJM Int. J. Med. 2015, 108, 273-277. [CrossRef]

22. Mohammadian-Behbahani, Z.; Jabbarzadeh, A.; Pishvaee, M.S. A robust optimisation model for sustainable blood supply chain network design under uncertainty. Int. J. Ind. Syst. Eng. 2019, 31, 475-494.

23. Boonyanusith, W.; Jittamai, P. Blood Supply Chain Risk Management using House of Risk Model. Walailak J. Sci. Technol. (WJST) 2018, 16, 573-591. [CrossRef]

24. Lu, Y.; Teng, F.; Zhou, J.; Wen, A.; Bi, Y. Failure mode and effect analysis in blood transfusion: A proactive tool to reduce risks. Transfusion 2013, 53, 3080-3087. [CrossRef] [PubMed]

25. Dehnavieh, R.; Ebrahimipour, H.; Molavi-Taleghani, Y.; Vafaee-Najar, A.; Noori Hekmat, S.; Esmailzdeh, H. Proactive risk assessment of blood transfusion process, in pediatric emergency, using the Health Care Failure Mode and Effects Analysis (HFMEA). Glob. J. Health Sci. 2014, 7, 322-331. [CrossRef] [PubMed]

26. Najafpour, Z.; Hasoumi, M.; Behzadi, F.; Mohamadi, E.; Jafary, M.; Saeedi, M. Preventing blood transfusion failures: FMEA, an effective assessment method. BMC Health Serv. Res. 2017, 17, 453. [CrossRef]

27. Cagliano, A.C.; Grimaldi, S.; Mangano, G.; Rafele, C. Risk Management in Hospital Wards: The Case of Blood Procurement and Handling. IFAC-PapersOnLine 2017, 50, 4648-4653. [CrossRef]

28. Achmadi, R.E.; Mansur, A. Design mitigation of blood supply chain using supply chain risk management approach. In Proceedings of the International Conference on Industrial Engineering and Operations Management, Bandung, Indonesia, 6-8 March 2018; pp. 1763-1772.

29. Jaberidoost, M.; Olfat, L.; Hosseini, A.; Kebriaeezadeh, A.; Abdollahi, M.; Alaeddini, M.; Dinarvand, R. Pharmaceutical supply chain risk assessment in Iran using analytic hierarchy process (AHP) and simple additive weighting (SAW) methods. J. Pharm. Policy Pract. 2015, 8, 9. [CrossRef]

30. Mora, A.; Ayala, L.; Bielza, R.; Ataúlfo González, F.; Villegas, A. Improving safety in blood transfusion using failure mode and effect analysis. Transfusion 2019, 59, 516-523. [CrossRef]

31. Gaudenzi, B.; Borghesi, A. Managing risks in the supply chain using the AHP method. Int. J. Logist. Manag. 2006, 17, 114-136. [CrossRef]

32. Wu, T.; Blackhurst, J.; Chidambaram, V. A model for inbound supply risk analysis. Comput. Ind. 2006, 57, 350-365. [CrossRef]

33. Pujawan, I.N.; Geraldin, L.H. House of risk: A model for proactive supply chain risk management. Bus. Process. Manag. J. 2009, 15, 953-967. [CrossRef]

34. Moeinzadeh, P.; Hajfathaliha, A. A combined fuzzy decision making approach to supply chain risk assessment. World Acad. Sci. Eng. Technol. 2009, 60, 519-528.

35. Wang, X.; Chan, H.K.; Yee, R.W.Y.; Diaz-Rainey, I. A two-stage fuzzy-AHP model for risk assessment of implementing green initiatives in the fashion supply chain. Int. J. Prod. Econ. 2012, 135, 595-606. [CrossRef]

36. Song, W.; Ming, X.; Liu, H.-C. Identifying critical risk factors of sustainable supply chain management: A rough strength-relation analysis method. J. Clean. Prod. 2017, 143, 100-115. [CrossRef]

37. Curkovic, S.; Scannell, T.; Wagner, B. Using FMEA for supply chain risk management. Mod. Manag. Sci. Eng. 2013, 1, 251-265.

38. Nazam, M.; Xu, J.; Tao, Z.; Ahmad, J.; Hashim, M. A fuzzy AHP-TOPSIS framework for the risk assessment of green supply chain implementation in the textile industry. Int. J. Supply Oper. Manag. 2015, 2, 548-568.

39. Fazli, S.; Kiani Mavi, R.; Vosooghidizaji, M. Crude oil supply chain risk management with DEMATEL-ANP. Oper. Res. 2015, 15, 453-480. [CrossRef]

40. Rostamzadeh, R.; Ghorabaee, M.K.; Govindan, K.; Esmaeili, A.; Nobar, H.B.K. Evaluation of sustainable supply chain risk management using an integrated fuzzy TOPSIS- CRITIC approach. J. Clean. Prod. 2018, 175, 651-669. [CrossRef]

41. Junaid, M.; Xue, Y.; Syed, M.W.; Li, J.Z.; Ziaullah, M. A Neutrosophic AHP and TOPSIS Framework for Supply Chain Risk Assessment in Automotive Industry of Pakistan. Sustainability 2019, 12, 154. [CrossRef]

42. Troche-Escobar, J.; Lepikson, H.; Freires, F. A Study of Supply Chain Risk in the Brazilian Wind Power Projects by Interpretive Structural Modeling and MICMAC Analysis. Sustainability 2018, 10, 3442. [CrossRef]

43. Khojasteh, Y. Developing Supply Chain Risk Mitigation Strategies. In Supply Chain Risk Management; Springer: Berlin/Heidelberg, Germany, 2018; pp. 97-103. 
44. Checkland, P.; Poulter, J. Soft systems methodology. In Systems Approaches to Managing Change: A Practical Guide; Springer: Berlin/Heidelberg, Germany, 2010; pp. 191-242.

45. Wang, W.; Liu, W.; Mingers, J. A systemic method for organisational stakeholder identification and analysis using Soft Systems Methodology (SSM). Eur. J. Oper. Res. 2015, 246, 562-574. [CrossRef]

46. Aryee, J.; Hansen, A.S. De-politicization of digital systems for trade facilitation at the port of tema: A soft systems methodology approach. Case Stud. Transp. Policy 2021, in press. [CrossRef]

47. Conte, K.P.; Davidson, S. Using a 'rich picture'to facilitate systems thinking in research coproduction. Health Res. Policy Syst. 2020, 18, 1-14. [CrossRef] [PubMed]

48. Hogan, B. Using Information Networks to Study Social Behavior: An Appraisal. IEEE Data Eng. Bull. 2007, 30, 6-14.

49. Burt, R.S.; Minor, M.J. Applied Network Analysis: A Methodological Introduction; SAGE Publications, Incorporated: Thousand Oaks, CA, USA, 1983.

50. Saito, K.; Kimura, M.; Ohara, K.; Motoda, H. Super mediator-A new centrality measure of node importance for information diffusion over social network. Inf. Sci. 2016, 329, 985-1000. [CrossRef]

51. Dawson, S. A study of the relationship between student social networks and sense of community. J. Educ. Technol. Soc. 2008, 11, 224-238.

52. Sun, H.; Geng, Y.; Hu, L.; Shi, L.; Xu, T. Measuring China's new energy vehicle patents: A social network analysis approach. Energy 2018, 153, 685-693. [CrossRef]

53. Hansen, D.; Shneiderman, B.; Smith, M.A. Analyzing Social Media Networks with NodeXL: Insights from a Connected World; Morgan Kaufmann: Berlington, MA, USA, 2010.

54. Warfield, J.N. Toward Interpretation of Complex Structural Models. IEEE Trans. Syst. Man Cybern. 1974, SMC-4, 405-417. [CrossRef]

55. Shakerian, M.; Jahangiri, M.; Alimohammadlou, M.; Nami, M.; Choobineh, A. Individual cognitive factors affecting unsafe acts among Iranian industrial workers: An integrative meta-synthesis interpretive structural modeling (ISM) approach. Saf. Sci. 2019, 120, 89-98. [CrossRef]

56. Poduval, P.S.; Pramod, V.R.; Jagathy Ray, V.P. Interpretive Structural Modeling (ISM) and its application in analyzing factors inhibiting implementation of Total Productive Maintenance (TPM). Int. J. Qual. Reliab. Manag. 2015, 32, 308-331. [CrossRef]

57. Christopher, M.; Peck, H. Building the resilient supply chain. CERES 2004, 15, 1-13. [CrossRef]

58. Kirılmaz, O.; Erol, S. A proactive approach to supply chain risk management: Shifting orders among suppliers to mitigate the supply side risks. J. Purch. Supply Manag. 2017, 23, 54-65. [CrossRef]

59. Fan, Y.; Stevenson, M. A review of supply chain risk management: Definition, theory, and research agenda. Int. J. Phys. Distrib. Logist. Manag. 2018, 48, 205-230. [CrossRef]

60. Snedaker, S. Business Continuity and Disaster Recovery Planning for IT Professionals; Newnes: Oxford, UK, 2013.

61. Jüttner, U.; Peck, H.; Christopher, M. Supply chain risk management: Outlining an agenda for future research. Int. J. Logist. Res. Appl. 2003, 6, 197-210. [CrossRef]

62. Buzacott, J.A.; Peng, H.S. Contract design for risk sharing partnerships in manufacturing. Eur. J. Oper. Res. 2012, 218, 656-666. [CrossRef]

63. Hoffmann, P.; Schiele, H.; Krabbendam, K. Uncertainty, supply risk management and their impact on performance. J. Purch. Supply Manag. 2013, 19, 199-211. [CrossRef] 